- Original Article

\title{
The Prevalence of Osteoarthritis and Risk Factors in the Korean Population: The Sixth Korea National Health and Nutrition Examination Survey (Vl-1, 2013)
}

Seokhan Lee, Yeongkeun Kwon, Nojin Lee, Keun-Joo Bae, Jihyun Kim, Seokwon Park, Yang Hyun Kim, Kyung-Hwan $\mathrm{Cho}^{*}$

Department of Family Medicine, Korea University College of Medicine, Seoul, Korea

Background: Knee osteoarthritis is highly prevalent, especially among the elderly. However, its risk factors have not been well identified, especially in the Korean population. This study aimed to assess the epidemiologic characteristics and risk factors of knee osteoarthritis in the Korean population.

Methods: Data of 2,280 (1,295 women) participants of the 2013 Korea National Health and Nutrition Examination Survey aged $\geq 50$ years who underwent knee radiography were analyzed. According to the American College of Rheumatology clinical/radiographic classification criteria, knee osteoarthritis was defined as knee pain and radiographic knee osteoarthritis. The association between risk factors and knee osteoarthritis was analyzed using the chi-square test and binominal logistic regression.

Results: The participants had an average age of 62.6 years; $56.8 \%$ of them were women. The average body mass index was $24.2 \mathrm{~kg} / \mathrm{m}^{2}$, and 296 (13\%) participants were diagnosed with knee osteoarthritis. After adjustment for multiple risk factors, age of $\geq 65$ years (adjusted odds ratio [OR], 2.552; 95\% confidence interval [CI], 1.868-3.486), female sex (OR, 2.050; 95\% CI, 1.275-3.295), obesity (body mass index, $\geq 25.0 \mathrm{~kg} / \mathrm{m}^{2} ; \mathrm{OR}, 1.563 ; 95 \% \mathrm{CI}, 1.191-2.051$ ), hypertension (OR, 1.394; 95\% CI, 1.052-1.846), low educational level (lower than or equal to elementary school: OR, 4.761; 95\% CI, 2.131-10.635; middle school: OR, 3.184; 95\% CI, 1.375-7.369), and low strength exercise frequency (<2 times/wk; OR, 1.829; 95\% CI, 1.202-2.784) increased the risk of knee osteoarthritis.

Conclusion: Old age, sex, obesity, hypertension, low educational level, and low strength exercise frequency were found to be risk factors for knee osteoarthritis.

Keywords: Epidemiology; Knee Osteoarthritis; Risk Factors; Radiography

Received: July 10, 2017, Revised: October 16, 2017, Accepted: October 17, 2018

${ }^{*}$ Corresponding Author: Kyung-Hwan Cho https://orcid.org/0000-0003-2521-3064

Tel: +82-2-920-5105, Fax: +82-2-928-8083, E-mail: chokh@korea.ac.kr 


\section{INTRODUCTION}

Knee osteoarthritis (OA) is a widely prevalent disorder causing knee pain and limitation in the performance of activities due to gradual deterioration and inflammation of the articular cartilage. The knee joint is a frequent site of OA-related pain, ${ }^{1,2)}$ especially in older age groups in which self-reported knee pain is commonly attributed to symptomatic and radiographic knee OA. Nearly 27 million American adults were reported to have clinical knee OA in 2008 (an increase from 21 million in 1995) ${ }^{3)}$ Knee OA seems to increase the risk of several negative outcomes and is associated with higher rates of hospitalization ${ }^{4)}$ and institutionalization $^{5)}$ and a higher risk of earlier death. ${ }^{6)}$ Therefore, it is important to identify individuals who have risk factors for knee OA at an early time point.

Previous studies have shown that older age, female sex, obesity, muscle weakness, hypertension, low educational level, and low household income were the risk factors for knee OA mainly in Caucasians. ${ }^{7-9)}$ While there are several risk factor studies on Caucasians, only a few population-based cohort studies have examined the risk factors for knee OA in the Asian population. Previously, there was a similar study on the Korean population; however, the risk factors were limited to age, sex, obesity, and quality of life. ${ }^{10)}$ In addition, one study reported race and severity of joint stiffness as risk factors for early radiographic changes; ${ }^{11)}$ research on other risk factors is lacking.

Therefore, the purpose of this study was to estimate the risk factors of knee OA in the Korean population. To evaluate the risk factors associated with knee OA, we studied a population-based group of Korean individuals aged $\geq 50$ years from the 2013 Korea National Health and Nutrition Examination Survey (KNHANES). We examined the risk factors for knee OA as well as knee pain. Radiologic information was evaluated using the Kellgren-Lawrence (K-L) grade. ${ }^{12}$ )

\section{METHODS}

\section{Study Population}

This cross-sectional study used data from the 2013 KNHANES managed and released by the Korea Centers for Disease Control and Prevention. These data were collected by the Korean government as basic data for examination and estimation of the general health state, health care perception and usage, food consumption, and nutritional status of the South Korean population at the national and regional (city and province) levels and for incorporation to public health care policy and policy evaluation. All participants provided written informed consent and were given the right to refuse to participate according to the National Health Enhancement Act. Because all KNHANES data are publicly available, this study did not require institutional review board approval.

Of 10,113 potential respondents, 8,018 $(79.3 \%)$ participated in the examination and survey. In this study, we excluded 5,006 participants under the age of 50 years and 239 participants over the age of 50 years who did not undergo knee radiography. An additional 493 participants who did not respond to the survey were excluded. Thus, the subjects of this study were limited to 2,280 participants aged $\geq 50$ years who received knee radiography and completed health survey sections on knee OA.

\section{Identification of Knee Osteoarthritis}

According to the American College of Rheumatology clinical/radiographic classification criteria, knee OA was defined as the presence of knee pain and at least one of the following three items along with osteophyte formation on knee radiographic images: age of $>50$ years, $<30$ minutes of morning stiffness, and crepitus upon knee motion. ${ }^{13)}$ Since all participants in our study were aged over 50 years, the presence of knee pain and radiographic knee OA were enough for the diagnosis. The presence of knee pain was identified using responses to a questionnaire. The K-L grade was adopted for the diagnosis of radiographic knee OA using knee radiography. The K-L grade, ${ }^{12)}$ a 5-level index ranging from 0 to 4 ( $0=$ none, $1=$ doubtful, $2=$ definite, $3=$ moderate, and $4=$ severe radiographic knee $\mathrm{OA}$ ), is a standard radiographic measurement of joint deterioration used in diagnosing and staging radiographic knee OA. Patients were considered to have radiographic knee OA when they had a K-L grade of $\geq 2$ on knee radiography in the 2013 KNHANES. ${ }^{12,14)}$

\section{Covariates}

The following baseline patient characteristics were assessed: age ( $\geq 65$ years or $<65$ years), sex, body mass index (BMI; $<25.0 \mathrm{~kg} / \mathrm{m}^{2}$ or $\geq 25.0$ $\left.\mathrm{kg} / \mathrm{m}^{2}\right)$, hypertension, diabetes, dyslipidemia, household income ( $<\$ 650, \$ 650$ to $<\$ 1,300, \$ 1,300$ to $<\$ 2,100$, or $\geq \$ 2,100$ ), educational level (lower than or equal to elementary school, middle school, high school, or higher than or equal to university), frequency of strength exercise ( $\geq 2$ times/wk or $<2$ times/wk), aerobic exercise ( $\geq 150$ minutes of moderate-intensity activity/wk or $<150$ minutes of moderate-intensity activity/wk), smoking status (non-smoker, ex-smoker, or current smoker), and alcohol consumption (no consumption, $\leq 1$ time/wk, or $>1$ time/wk). For the assessment of the patient-reported knee pain status, the numerical rating scale score (from 0 to 10) was used through self-reported questionnaires. BMI was calculated as weight in kilograms divided by height in meters squared. The World Health Organization (WHO) Asia Pacific BMI cutoff point of $<25.0 \mathrm{~kg} / \mathrm{m}^{2}$ or $\geq 25.0 \mathrm{~kg} /$ $\mathrm{m}^{2}$ was used to define obesity. ${ }^{15)}$

Hypertension and diabetes were identified as risk factors in the selfreported questionnaire based on the diagnosis provided by doctors. Dyslipidemia was defined by the levels of total cholesterol ( $\geq 240 \mathrm{mg}$ / $\mathrm{dL})$, high-density lipoprotein cholesterol ( $<40 \mathrm{mg} / \mathrm{dL}$ ), triglycerides ( $\geq 200 \mathrm{mg} / \mathrm{dL}$ ), and low-density lipoprotein cholesterol ( $\geq 160 \mathrm{mg} / \mathrm{dL}$ ) according to the National Cholesterol Education Program-Adult Treatment Panel III guidelines ${ }^{16)}$ and based on whether the participants indicated that they were taking medications to lower their cholesterol levels in the self-reported questionnaire.

Strength exercises included arm-pushing, sit-ups, and use of dumbbells, weights, and barbells; the subjects were divided into two groups 
according to the frequency of performance of these exercises: $\geq 2$ times/wk or $<2$ times/wk. For aerobic exercises, the subjects were divided into two groups according to whether the weekly moderate-intensity aerobic physical activity duration was $>150$ minutes.

According to the smoking status, the subjects were classified into three groups: non-smoker, ex-smoker, or current smoker. Participants smoking daily or occasionally were defined as current smokers. Those who answered that they smoked in the past but do not currently smoke were defined as ex-smokers, while the remaining participants were defined as non-smokers. According to the frequency of alcohol consumption, the subjects were divided into three groups: no consumption, $\leq 1$ time/wk, or $>1$ time/wk.

\section{Statistical Analysis}

For the baseline characteristics analysis, data were expressed as numbers and percentages. The chi-square test was used to compare the frequency in each group with knee OA and to identify the risk factors

Table 1. Baseline characteristics of the study population according to the presence of knee osteoarthritis

\begin{tabular}{|c|c|c|c|}
\hline \multirow{2}{*}{ Characteristic } & \multicolumn{2}{|c|}{ Knee osteoarthritis } & \multirow{2}{*}{ - P-value } \\
\hline & $(-)$ & $(+)$ & \\
\hline Participants & $1,984(87.0)$ & $296(13.0)$ & \\
\hline Female sex & $1,070(53.9)$ & $225(76.0)$ & $<0.001$ \\
\hline Age $\geq 65$ y & $720(36.3)$ & 202 (68.2) & $<0.001$ \\
\hline $\mathrm{BMI} \geq 25.0 \mathrm{~kg} / \mathrm{m}^{2}$ & $682(34.4)$ & $142(48.0)$ & $<0.001$ \\
\hline Hypertension & $682(34.4)$ & $157(53.0)$ & $<0.001$ \\
\hline Diabetes & $286(14.4)$ & $70(23.6)$ & $<0.001$ \\
\hline Dyslipidemia & $1,056(53.2)$ & $164(55.4)$ & 0.483 \\
\hline $\begin{array}{l}\text { Strength exercise frequency } \\
<2 \text { times/wk }\end{array}$ & $1,508(76.0)$ & $266(89.9)$ & $<0.001$ \\
\hline Aerobic exercise $<150 \mathrm{~min} / \mathrm{wk}$ & $1,870(94.3)$ & $282(95.3)$ & 0.479 \\
\hline Smoking status & & & $<0.001$ \\
\hline Current smoker & $324(16.3)$ & $31(10.5)$ & \\
\hline Ex-smoker & $501(25.3)$ & $44(14.9)$ & \\
\hline Non-smoker & $1,159(58.4)$ & $221(74.7)$ & \\
\hline Alcohol consumption & & & $<0.001$ \\
\hline$>1$ time/wk & $408(20.6)$ & 39 (13.2) & \\
\hline$\leq 1$ time/wk & $860(43.3)$ & $107(36.1)$ & \\
\hline No & $716(36.1)$ & $150(50.7)$ & \\
\hline Household income ${ }^{\dagger}(\$)$ & & & $<0.001$ \\
\hline$\geq 2,100$ & $488(24.6)$ & $33(11.1)$ & \\
\hline $1,300-2,100$ & $452(22.8)$ & $52(17.6)$ & \\
\hline $650-1,300$ & $525(26.5)$ & $66(22.3)$ & \\
\hline$<650$ & $519(26.2)$ & $145(49.0)$ & \\
\hline Educational level & & & $<0.001$ \\
\hline Higher than or equal to university & $290(14.6)$ & $7(2.4)$ & \\
\hline High school & $596(30.0)$ & $38(12.8)$ & \\
\hline Middle school & $357(18.0)$ & $40(13.5)$ & \\
\hline $\begin{array}{l}\text { Lower than or equal to } \\
\text { elementary school }\end{array}$ & 741 (37.3) & 211 (71.3) & \\
\hline
\end{tabular}

Values are presented as number (\%) for categorical variables. BMI was calculated as weight in kilograms divided by height in meters squared.

BMl, body mass index.

${ }^{*}$ Obtained using Pearson's chi-square test. 'To distinguish household income, we referred to the standard amount of income quartile of the sample households. associated with knee OA (Table 1). The chi-square test and binominal logistic regression were used for the univariate and multivariate analyses, respectively, and to evaluate the odds ratio (OR) for measuring the association between the risk factors and knee OA (Table 2). Binominal logistic regression analyses were conducted, adjusting for age, sex, BMI, hypertension, diabetes, dyslipidemia, household income, educational level, and lifestyle habits, including smoking, alcohol consumption, frequency of strength exercise, and aerobic exercise. For the subjects in the 2013 KNHANES to represent the entire Korean population, we applied sampling weights to take the complex sampling method into account. All tests were two-tailed, and a P-value of $<0.05$ was interpreted as significant. The data collected were collated and analyzed using the IBM SPSS ver. 20.0 for Windows (IBM Corp., Armonk, NY, USA).

\section{RESULTS}

\section{Baseline Characteristics}

The mean age of the 2,280 subjects in this study was 62.6 years, and 1,295 participants (56.8\%) were women. Of the 2,280 participants, 296 (13\%) had knee OA, and 1,984 (87\%) had no knee OA (Table 1). Old age ( $\geq 65$ years), female sex, obesity (BMI $\geq 25.0 \mathrm{~kg} / \mathrm{m}^{2}$ ), hypertension, diabetes, and low frequency of strength exercise were more common in the participants who were diagnosed with knee OA than in those who were not $(\mathrm{P}<0.001)$. Smokers and drinkers were further divided into three subgroups. In each subgroup, the proportion of participants in each group of non-smokers and non-drinkers was higher in the group with knee $\mathrm{OA}$ than in the group without $(\mathrm{P}<0.001)$. The proportion of participants who were diagnosed with knee OA gradually increased as the household income decreased and educational level became low $(\mathrm{P}<0.001)$. However, aerobic exercise $(\mathrm{P}=0.479)$ and dyslipidemia $(\mathrm{P}=0.483)$ did not show a significant correlation with knee OA. Therefore, all the factors, except for dyslipidemia and aerobic exercise, were associated with knee OA (Table 1).

\section{Identification of Risk Factors}

The association between each risk factor and development of knee OA is presented in Table 2. Old age ( $>65$ years; adjusted OR, 2.552; 95\%; confidence interval [CI], 1.868-3.486) and low educational level (lower than or equal to elementary: OR, 4.761; 95\% CI, 2.131-10.635; middle school: OR, 3.184; 95\% CI, 1.375-7.369) were strongly associated with an increased risk of knee OA. The participants with female sex (OR, 2.050; 95\% CI, 1.275-3.295), low frequency of strength exercise $(<2$ times/wk; OR, 1.829; 95\% CI, 1.202-2.784), obesity (BMI $\geq 25.0 \mathrm{~kg} / \mathrm{m}^{2}$; OR, 1.563; 95\% CI, 1.191-2.051), and hypertension (OR, 1.394; 95\% CI, 1.052-1.846) displayed a significantly higher prevalence of knee OA $(\mathrm{P}<0.05)$. Those with diabetes and low household income (less than or equal to middle low), non-smokers, and non-drinkers displayed a higher prevalence of knee OA in the univariate analysis. However, diabetes, low household income, non smokers, non drinker was removed in the logistic regression analysis using the backward elimination 
Table 2. Relationship between risk factors and knee osteoarthritis

\begin{tabular}{|c|c|c|c|c|}
\hline \multirow{2}{*}{ Covariates } & \multicolumn{2}{|c|}{ Univariate } & \multicolumn{2}{|c|}{ Multivariate } \\
\hline & $\mathrm{OR}(95 \% \mathrm{Cl})$ & P-value ${ }^{*}$ & $\mathrm{OR}(95 \% \mathrm{Cl})^{\dagger}$ & P-value* \\
\hline Female sex & $2.707(2.044-3.585)$ & $<0.001$ & $2.050(1.275-3.295)$ & 0.003 \\
\hline Age $\geq 65 y$ & $3.773(2.905-4.899)$ & $<0.001$ & $2.552(1.868-3.486)$ & $<0.001$ \\
\hline $\mathrm{BMI} \geq 25.0 \mathrm{~kg} / \mathrm{m}^{2}$ & $1.760(1.376-2.252)$ & $<0.001$ & $1.563(1.191-2.051)$ & 0.001 \\
\hline Hypertension & $2.156(1.685-2.759)$ & $<0.001$ & $1.394(1.052-1.846)$ & 0.021 \\
\hline Diabetes & $1.839(1.368-2.472)$ & $<0.001$ & $1.236(0.883-1.730)$ & 0.216 \\
\hline Dyslipidemia & $1.092(0.854-1.396)$ & 0.483 & $0.842(0.640-1.108)$ & 0.220 \\
\hline Strength exercise frequency $<2$ times/wk & $2.799(1.892-4.139)$ & $<0.001$ & $1.829(1.202-2.784)$ & 0.005 \\
\hline Aerobic exercise $<150 \mathrm{~min} / \mathrm{wk}$ & $1.228(0.695-2.169)$ & 0.479 & $0.706(0.379-1.318)$ & 0.274 \\
\hline \multicolumn{5}{|l|}{ Smoking status } \\
\hline Current smoker & 1.000 & 0.727 & 1.000 & 0.304 \\
\hline Ex-smoker & $0.918(0.568-1.484)$ & 0.001 & $0.764(0.458-1.276)$ & 0.618 \\
\hline Non-smoker & $1.993(1.342-2.960)$ & & $0.874(0.516-1.481)$ & \\
\hline \multicolumn{5}{|l|}{ Alcohol consumption } \\
\hline$>1$ time/wk & 1.000 & 0.180 & 1.000 & 0.696 \\
\hline$\leq 1$ time/wk & $1.302(0.886-1.913)$ & $<0.001$ & $0.917(0.594-1.416)$ & 0.953 \\
\hline No & $2.192(1.510-3.181)$ & & $0.987(0.632-1.539)$ & \\
\hline \multicolumn{5}{|l|}{ Household income ${ }^{\ddagger}(\$)$} \\
\hline$\geq 2,100$ & 1.000 & 0.022 & 1.000 & 0.579 \\
\hline $1,300-2,100$ & $1.701(1.080-2.680)$ & 0.005 & $1.147(0.707-1.860)$ & 0.701 \\
\hline $650-1,300$ & $1.859(1.203-2.874)$ & $<0.001$ & $0.911(0.568-1.463)$ & 0.222 \\
\hline$<650$ & $4.131(2.776-6.149)$ & & $1.330(0.841-2.103)$ & \\
\hline \multicolumn{5}{|l|}{ Educational level } \\
\hline Higher than or equal to university & 1.000 & 0.020 & 1.000 & 0.072 \\
\hline High school & $2.641(1.165-5.987)$ & $<0.001$ & 2.141 (0.933-4.912) & 0.007 \\
\hline Middle school & $4.642(2.049-10.516)$ & $<0.001$ & $3.184(1.375-7.369)$ & $<0.001$ \\
\hline Lower than or equal to elementary school & $11.797(5.489-25.354)$ & & $4.761(2.131-10.635)$ & \\
\hline
\end{tabular}

OR, odds ratio; $\mathrm{Cl}$, confidence interval; BMl, body mass index.

${ }^{*}$ ORs $\left(95 \% \mathrm{Cls}\right.$ ) and P-values were estimated using the chi-square test and binominal logistic regression analyses. ${ }^{\dagger}$ Fully adjusted for sex, age, BMl, hypertension, diabetes, dyslipidemia, strength exercise frequency, aerobic exercise, smoking status, alcohol consumption, household income, and educational level. ₹To distinguish household income, we referred to the standard amount of income quartile of the sample households.

method because the P-value was $>0.10$ (Table 2).

\section{DISCUSSION}

We compared the prevalence of knee OA among groups after setting subgroups based on the risk factors for knee OA known from previous studies in men and women aged over 50 years who participated in the 2013 KNHANES. This study suggests that the following risk factors increase the risk of knee OA: old age ( $\geq 65$ years), female sex, obesity (BMI $\geq 25.0 \mathrm{~kg} / \mathrm{m}^{2}$ ), hypertension, low frequency of strength exercise ( $<2$ times/wk), and low educational level (lower than or equal to middle school). This study confirmed that the risk factors revealed in previous studies were the same as those revealed in our study on the Korean population. ${ }^{7,10,17-22)}$

Although, household income has been identified as a risk factor in previous studies ${ }^{22)}$ and is associated with weight gain, ${ }^{23)}$ it was not found to be a risk factor for knee OA in this study. Therefore, further research in this aspect is needed. Both the diabetic and non-diabetic groups did not show any difference in the prevalence of knee OA. Although dyslipidemia is associated with overweight and obesity, it was not a risk factor for knee OA. ${ }^{16,21)}$ Smokers had a lower risk than did non-smokers, which may also be related to the effect of non-smoking on weight gain. ${ }^{18,23)}$ Less physical activity was associated with weight gain. ${ }^{23)}$ However, less aerobic exercise was not associated with knee OA in this study. Alcohol consumption was associated with hand $\mathrm{OA}^{24)}$ Although hand $\mathrm{OA}$ is a risk factor for knee $\mathrm{OA},{ }^{20)}$ there is still a lack of research on the relationship between knee OA and alcohol consumption.

This study has some limitations. First, since this study was a crosssectional study, it was difficult to elucidate a causal relationship between knee OA and the risk factors. Second, although there remains a controversy regarding the knee OA classification system, specialists have agreed that knee OA diagnosis should be based on radiologic features, and the WHO has adopted the K-L grade as a standard criterion. ${ }^{12,25)}$ Third, patients with vitamin D deficiency and low quality of life are known to be at an increased risk of knee OA. ${ }^{10,26)}$ However, such patients were not included in this study, and comparisons could not be made with previous studies.

Some strengths of this study include the fact that it employed radiologic imaging in the analysis of a large patient data sample representing the Korean population; further, the health survey, examination, and radiographic readings were performed systematically by trained 
experts. Conversely, several previous studies are limited in that they used hospital data in limited patient pools, which may have increased their susceptibility to selection bias.

In conclusion, the analysis of the associations between knee OA and risk factors in Koreans aged $\geq 50$ years using nationally representative data of the 2013 KNHANES revealed that old age ( $\geq 65$ years), female sex, obesity (BMI $\geq 25.0 \mathrm{~kg} / \mathrm{m}^{2}$ ), hypertension, low frequency of strength exercise ( $<2$ times/wk), and low educational level (lower than or equal to middle school) were the risk factors for knee OA.

\section{CONFLICT OF INTEREST}

No potential conflict of interest relevant to this article was reported.

\section{ORCID}

Seokhan Lee: https://orcid.org/0000-0002-5025-1452

Kyung-Hwan Cho: https://orcid.org/0000-0003-2521-3064

\section{REFERENCES}

1. Urwin M, Symmons D, Allison T, Brammah T, Busby H, Roxby M, et al. Estimating the burden of musculoskeletal disorders in the community: the comparative prevalence of symptoms at different anatomical sites, and the relation to social deprivation. Ann Rheum Dis 1998;57: 649-55.

2. Thomas E, Peat G, Harris L, Wilkie R, Croft PR. The prevalence of pain and pain interference in a general population of older adults: crosssectional findings from the North Staffordshire Osteoarthritis Project (NorStOP). Pain 2004;110:361-8.

3. Lawrence RC, Felson DT, Helmick CG, Arnold LM, Choi H, Deyo RA, et al. Estimates of the prevalence of arthritis and other rheumatic conditions in the United States: part II. Arthritis Rheum 2008;58:26-35.

4. Murphy L, Helmick CG. The impact of osteoarthritis in the United States: a population-health perspective. Am J Nurs 2012;112(3 Suppl 1):S13-9.

5. Guccione AA, Meenan RF, Anderson JJ. Arthritis in nursing home residents: a validation of its prevalence and examination of its impact on institutionalization and functional status. Arthritis Rheum 1989;32: 1546-53.

6. Liu Q, Niu J, Huang J, Ke Y, Tang X, Wu X, et al. Knee osteoarthritis and all-cause mortality: the Wuchuan Osteoarthritis Study. Osteoarthritis Cartilage 2015;23:1154-7.

7. Mili F, Helmick CG, Zack MM. Prevalence of arthritis: analysis of data from the US Behavioral Risk Factor Surveillance System, 1996-99. J Rheumatol 2002;29:1981-8.

8. Veronese N, Stubbs B, Solmi M, Smith TO, Noale M, Schofield P, et al. Knee osteoarthritis and risk of hypertension: a longitudinal cohort study. Rejuvenation Res 2018;21:15-21.

9. Eitner A, Pester J, Vogel F, Marintschev I, Lehmann T, Hofmann GO, et al. Pain sensation in human osteoarthritic knee joints is strongly enhanced by diabetes mellitus. Pain 2017;158:1743-53.

10. Lee S, Kim SJ. Prevalence of knee osteoarthritis, risk factors, and quali- ty of life: the fifth Korean National Health And Nutrition Examination Survey. Int J Rheum Dis 2017;20:809-17.

11. Mazzuca SA, Brandt KD, Katz BP, Ding Y, Lane KA, Buckwalter KA. Risk factors for early radiographic changes of tibiofemoral osteoarthritis. Ann Rheum Dis 2007;66:394-9.

12. Kellgren JH, Lawrence JS. Radiological assessment of osteo-arthrosis. Ann Rheum Dis 1957;16:494-502.

13. Altman R, Asch E, Bloch D, Bole G, Borenstein D, Brandt K, et al. Development of criteria for the classification and reporting of osteoarthritis: classification of osteoarthritis of the knee. Diagnostic and Therapeutic Criteria Committee of the American Rheumatism Association. Arthritis Rheum 1986;29:1039-49.

14. Eckstein F, Wirth W, Nevitt MC. Recent advances in osteoarthritis imaging: the osteoarthritis initiative. Nat Rev Rheumatol 2012;8:622-30.

15. World Health Organization. The Asia-Pacific perspective: redefining obesity and its treatment. Sydney: Health Communications Australia; 2000.

16. Expert Panel on Detection, Evaluation, and Treatment of High Blood Cholesterol in Adults. Executive summary of the third report of the National Cholesterol Education Program (NCEP) Expert Panel on Detection, Evaluation, and Treatment of High Blood Cholesterol in Adults (Adult Treatment Panel III). JAMA 2001;285:2486-97.

17. Hart DJ, Doyle DV, Spector TD. Association between metabolic factors and knee osteoarthritis in women: the Chingford Study. J Rheumatol 1995;22:1118-23.

18. Felson DT, Zhang Y, Hannan MT, Naimark A, Weissman B, Aliabadi P, et al. Risk factors for incident radiographic knee osteoarthritis in the elderly: the Framingham Study. Arthritis Rheum 1997;40:728-33.

19. Slemenda C, Heilman DK, Brandt KD, Katz BP, Mazzuca SA, Braunstein EM, et al. Reduced quadriceps strength relative to body weight: a risk factor for knee osteoarthritis in women? Arthritis Rheum 1998;41:1951-9.

20. Blagojevic M, Jinks C, Jeffery A, Jordan KP. Risk factors for onset of osteoarthritis of the knee in older adults: a systematic review and metaanalysis. Osteoarthritis Cartilage 2010;18:24-33.

21. Niu J, Clancy M, Aliabadi P, Vasan R, Felson DT. Metabolic syndrome, its components, and knee osteoarthritis: the Framingham Osteoarthritis Study. Arthritis Rheumatol 2017;69:1194-203.

22. Jorgensen KT, Pedersen BV, Nielsen NM, Hansen AV, Jacobsen S, Frisch M. Socio-demographic factors, reproductive history and risk of osteoarthritis in a cohort of 4.6 million Danish women and men. Osteoarthritis Cartilage 2011;19:1176-82.

23. Lahmann PH, Lissner L, Gullberg B, Berglund G. Sociodemographic factors associated with long-term weight gain, current body fatness and central adiposity in Swedish women. Int J Obes Relat Metab Disord 2000;24:685-94.

24. Magnusson K, Mathiessen A, Hammer HB, Kvien TK, SlatkowskyChristensen B, Natvig B, et al. Smoking and alcohol use are associated with structural and inflammatory hand osteoarthritis features. Scand J Rheumatol 2017;46:388-95.

25. Culvenor AG, Engen CN, Oiestad BE, Engebretsen L, Risberg MA. Defining the presence of radiographic knee osteoarthritis: a comparison between the Kellgren and Lawrence system and OARSI atlas criteria. Knee Surg Sports Traumatol Arthrosc 2015;23:3532-9.

26. Zhang FF, Driban JB, Lo GH, Price LL, Booth S, Eaton CB, et al. Vitamin D deficiency is associated with progression of knee osteoarthritis. J Nutr 2014;144:2002-8. 